\title{
Creating the leadership you seek Five leadership development activities that will cultivate leadership from within your library
}

A early as 1986, academic librarians began anticipating the "graying of the profession" and predicting the impending crisis of workforce, particularly for leadership. ${ }^{1}$ They commonly suggest that the mass departure of baby boomers from the workforce will leave libraries struggling to find qualified leaders with the vision and knowledge necessary to propel the profession into the 21st century. Thirty years later, librarians are still concerned about not having sufficient future leadership. Leadership forums at national, regional, and local conferences and meetings often include one or more sessions that discuss the issue. However, besides mentorship and delayed retirement, very few viable longterm strategies are offered for handling the potential loss of leadership.

One solution not readily offered but worthy of strong consideration is positioning the qualified, capable workforce already employed in libraries to fill those gaps. This is accomplishable through five leadership activities: developing organization-specific leadership competencies, identifying individuals with leadership potential, honing leadership skills through professional development, creating opportunities for leadership, and succession planning.

\section{Develop organization-specific leadership competencies}

Developing leadership competencies that are measurable, justifiable, and easily attached to other performance indicators (e.g., annual review) allows libraries to benchmark leadership progression. To achieve this, library administrators might consider working with the library or university's human resources manager or a consultant to develop a set of core leadership competencies that are essential for potential leaders working in their library. This list would consist of general and organizational-culture specific competencies that address the skills and personal attributes necessary to provide leadership within a specific organization. ${ }^{2}$ Some commonly listed attributes for leadership include: ${ }^{3,4}$

- flexibility, adaptability, and a willingness to accept and manage change;

- visionary, strategic planning, and resource management;

- cultural competence;

- advocacy;

- ability to set priorities, manage time, and multi-task;

- innovation and collaboration;

- self-awareness, self-knowledge, and emotional intelligence;

- decision-making and problem-solving ability;

- understanding of library trends; and

- influence.

\section{Identifying potential leaders}

Working to identify potential leaders can prove challenging in academic libraries

Kimberley Bugg is assistant professor and reference coordinator at the NYC College of Technology, email: kbugg@citytech.cuny.edu

c 2016 Kimberley Bugg 
because not everyone with the potential for leadership has received an opportunity to demonstrate that capacity. Additionally, libraries often allow a great deal of autonomy, which does not always provide staffers the occasion to showcase their leadership skills. As a result, library administrators should make every effort to look beyond those librarians with assigned leadership roles to ascertain if other individuals with emergent leadership characteristics demonstrate the potential for future library leadership.

John Lubans Jr. describes these individuals as organizational spark plugs. A spark plug is someone with high energy, emotional intelligence, good humor, people skills, and a can-do attitude. They are highly promotable because they help the organization realize important objectives, act on good ideas, initiate, need little encouragement, follow through, and collaborate." 5

\section{Honing leadership}

Once the library administration has identified the individuals who show potential for library leadership in the future, they should begin honing their leadership skills through professional development. Both internal and external programs can serve to address leadership development. Internal programs will allow the library to customize the training towards their organizational culture and personalize the programs to address individual strengths and weaknesses. Internal library leadership development programs can be highly effective and, depending on structure, a budget-friendly method to develop leadership within a particular library.

Additionally, internal programs allow the library the flexibility to develop individuals over time and can vary in format. For example, Washington State University (WSU) Libraries created an internal leadership training program that offered a combination of presentations on leadership style, mini case studies, and discussion group activities.

Because the program was maintained internally, WSU was able to change topics and build on individual skills from one cohort to the next. ${ }^{6}$

External leadership training programs are also an option for developing individuals within the library who demonstrate leadership potential. External leadership programs give individuals an opportunity to learn from industry leaders and develop a network of peers to use as resources. Moreover, because the pool of prospective applicants is larger for association-level leadership programs, they can also target specific groups of individuals, such as minorities or beginning professionals.

Within the field of library science, many associations host librarian leadership programs that focus on leadership at various career stages. ALA sponsors a leadership institute that provides a four-day immersion into leadership preparation and personal development. This institute, led by pastALA president Maureen Sullivan and former ACRL content strategist Kathryn Deiss, offers structured learning focused on the midcareer librarian (five years or more) with a leadership background and an interest in greater leadership roles.

The Association of Research Libraries (ARL) offers two leadership institutes. The Leadership \& Career Development Program is aimed at midcareer, ethnic minority librarians and The ARL Leadership Fellows Program which targets executive library leaders. These programs are unique because they function over an extended period of time-18 and 12 months, respectively. Numerous other national, regional, and university associations offer leadership training opportunities for librarians demonstrating the potential for leadership, including Harvard Graduate School for Education.

\section{Creating opportunities for leadership}

Once you have identified individuals in your library with leadership potential and given them opportunities to develop their leadership skills through either internal or external initiatives, then allow them to lead. This may be challenging for libraries with a hierarchi- 
cal organizational structure because libraries that follow the higher education model of fixed appointments and long-tenured staff, may not have the flexibility to create new or short-term positions. However, the opportunities still can exist.

For example, the Robert W. Woodruff Library of the Atlanta University Center (RWWL) created two internal coordinator positions. In the case of the RWWL, librarians on the research and instruction team who show talent for leadership positions are given the opportunity to apply, interview, and potentially serve as either a coordinator of selection or instruction. The coordinator position lasts for three years, and the appointee oversees one or more library projects in the area. The coordinator is responsible for all administrative duties associated with position, including developing budgets and annual reports. Coordinators are reviewed annually by members of their team and the unit head. This process allows the coordinator to benefit from increased management exposure and accountability on a leadership level while assuming an opportunity to "try on" leadership before committing to it. ${ }^{7}$

Another option for libraries in close proximity to each other or who are a part of the same regional association is to partner to provide short-term leadership opportunities.

For example, Pennsylvania Academic Library Consortium, Inc. (PALCI) and Northern Pacific Library Association could create and maintain a library leadership exchange program. Ideally, individuals with potential for leadership who work for libraries without open positions or who are not ready to assume a full-time position will gain some leadership experience by working temporarily with a different organization.

Recently, the Association of Southeastern Research Libraries (ASERL) partnered with the HBCU Alliance to facilitate a leadership exchange program. In this partnership, librarians participating in the program spent two weeks at the partnering institution working in various leadership capacities. Similar programs also exist outside of the library profession. The Memphis Leadership Exchange and the International Visitor Leadership Program support similar arrangements for longer periods of time.

\section{Succession planning}

Finally, libraries must commit to the longterm leadership potential of these individuals by planning for them to lead the organization in the future. This succession planning not only benefits the individual, but the organization benefits from continual, effective leadership, while knowing that the current leadership may retire or leave for other positions.

Succession planning, like strategic planning, is a forecast of how the library plans to respond to environmental changes. Successful succession planning shows the current library leadership and those with leadership potential what the staffing needs might be so that together both groups can begin to prepare for those needs. For that reason, best practices for succession planning suggest that organizations: ${ }^{8}$

- keep it the plan simple, easy to use, and readily accessible;

- open process to all employees;

- secure involvement of all key players;

- analyze the organization's workforce;

- identify and prioritize workforce gaps;

- identify individuals within the organization who might makeup the pipeline; and

- follow-up with individuals identified through career planning and mentoring.

The process focuses on preparing the library to handle potential workforce gaps rather than prepping individuals to fill specific jobs so that individuals throughout the library are ready to lead. The succession planning process also has the potential to foster mentorships between individuals with current leadership responsibility and individuals with the potential to assume that responsibility. While succession planning is mentioned last, it does not necessarily come last. In fact, it can actually be the reason why the above-mentioned strategies are implemented. 


\section{Conclusion}

In an effort to lure those interested in managerial leadership, verbiage can be added to employment descriptions that briefly explain the leadership training possibilities connected to that position. Providing professional development opportunities and whole staff in-service events will allow time for those who are interested in leadership to gain the experience needed, while serving as a springboard for identifying those employees who may not have considered leadership.

Identifying personal characteristics and personality traits early on will give library administrators the information they need to build leadership programs that will hone in on employees' personal strength, which could potentially develop them for leadership opportunities. Once employees' selfefficacy is increased, they are more likely to believe in their capabilities to lead and as a result, pursue leadership positions.

Administrators across the profession must work cohesively to ensure that adequate leadership is in place to maintain and properly manage the vast amounts of information accessible in the world's libraries. No longer does the luxury exist where library administrators can solely focus on the needs of their particular program, they must now offer training and development programs that will instill the skills in future library leadership professionals needed to be successful in the field as a whole. Libraries within the same system or in close proximity can work collaboratively to create projects that provide leadership opportunities, while increasing the possibility of networking and sharing ideas.

Ultimately, libraries already employ the leaders that they seek, they need only to cultivate the potential of leadership within.

\section{Notes}

1. J. Berry, "Problems of a "graying" profession," Library Journal, 1116.

2. Beth McNeil, "Core competencies for libraries and library staff," (Chicago: ALA, 2001): 49-62.
3. Shorette Ammons-Stephens, Holly J. Cole, Catherine Fraser Riehle, and William H. Weare, "Developing core leadership competencies for the library profession," Library Leadership \& Management 23, no. 2 (2009): 63-74.

4. P. Hernon, R. R. Powell, and A. P. Young, "University library directors in the Association of Research Libraries: The next generation, part one," College \& Research Libraries, 62, no. 2, 116-46.

5. John Lubans Jr., "Leading from the middle: The Spark Plug: A Leader's Catalyst for Change," Library Leadership \& Management 23, no. 2 (2009): 88.

6. Alex N. Merrill and Elizabeth Blakesley Lindsay, "Growing your own: Building an internal leadership training program," Library Leadership \& Management 23, no. 2 (2009): 85-87.

7. R. Odom, personal communication.

8. Pat Hawthorne, "Succession planning and management: A key leadership responsibility emerges," Texas Library Journal 87, no. 1 (2011): 8-12. 2

\section{JObLIST章 The \#1 source for jobs in Library and Information Science and Technology}

\section{JOB SEEKERS}

Refine your search-filter and sort hundreds of job ads by position type, employer, location, job title, and more. Automate-easily create customized job alerts on the fly.

\section{EMPLOYERS}

Simplify recruitment-flat-rate pricing, discounted multi-ad packages, and optional enhanced postings available for increased visibility.

ALA HRDR ACRL

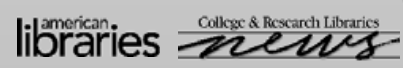
joblist.ala.org 